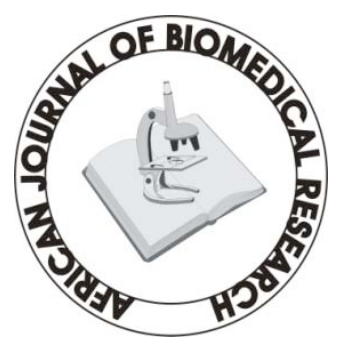

Full-text available at http://www.ajbrui.com http://www.bioline.br/md http://www.ajol.com

Received:

August 2007

Accepted (Revised): July 2008

Published

Septemeber 2008
Review Article

\section{Antimicrobial chemotherapy and Sustainable Development: The past, The Current Trend, and the future}

\author{
${ }^{* 1}$ Okonko I.O, ${ }^{2}$ Fajobi E.A, ${ }^{3}$ Ogunnusi T.A, ${ }^{3}$ Ogunjobi A.A. and \\ ${ }^{3}$ Obiogbolu C.H.
}

${ }^{I}$ Department of Virology, Faculty of Basic Medical Sciences, College of Medicine, University of Ibadan, University College Hospital (UCH), Ibadan, Nigeria

${ }^{2}$ Department of Basic Sciences, Federal College of Wildlife Management, New Bussa, Niger State, Nigeria

${ }^{4}$ Microbiology Unit, Department of Botany and Microbiology, University of Ibadan, Ibadan

\begin{abstract}
Antimicrobial chemotherapy is a highly valued medical science which has shaped modern humanity in a phenomenal fashion. Within the past half century, a wide variety of antimicrobial substances have been discovered, designed and synthesized; literally hundreds of drugs have been successfully used in some fashion over the years. Today, the world wide anti-infective market exceeds \$20 billion dollars annually and overall antimicrobial agents comprise the bulk of this trade. A number of general classes of antimicrobial drugs have emerged as mainstays in modern infectious disease chemotherapy. Regardless of a better understanding of infectious disease pathogenesis and the importance of sanitation, most individuals will become infected with a microbial pathogen many times, throughout their lives and in developed countries, anti-infective chemotherapy will be periodically administered. Antibacterial amount for the majority of antiinfective agents in comparison to antifungals, antivirals and antiparasitic agents. An antimicrobial is a chemical substance produced by microorganisms that can inhibit the growth of, or kill other microorganisms. The goal of antimicrobial in disease such as gastroenteritis is to decrease stool water and electrolyte losses, thus limiting the morbidity resulting from dehydration. Most antiretroviral only suppress the pathogen and boast the immune status but does not provide cure. To date, several drugs have been tried in the treatment of acute diseases such as diarrhea, HIV/AIDS but none has met the requirements enumerated above. They are therefore of very limited value in the department of diarrhea, especially in children as well in department of HIV/AIDS

(Afr. J. Biomed. Res. 11: 235 - 250 )
\end{abstract}

Key Words; Antimicrobials, microbial resistance, diseases

*Corresponding author: mac2finney@yahoo.com

Abstracted by:

African Index Medicus (WHO), CAB Abstracts, Index Copernicus, Global Health Abstracts, Asian Science Index, Index

Veterinarius, Bioline International, African Journals online 


\section{BACKGROUND}

Most antimicrobial are called antibiotics, literally meaning "against life". This is an ironic label for a group of drugs that have saved millions of lives over the last half century. They attack the microorganisms that have threatened humankind for thousands of years. While antibiotics have won many battles, they have not won the war by any means. The clever enemy keeps changing and coming back stronger than ever. Antibacterial chemotherapy is a highly valued medical science which has shaped modern humanity in a phenomenal fashion. Within the past half century, a wide variety of antibacterial substances have been discovered, designed and synthesized; literally hundreds of drugs have been successfully used in some fashion over the years. Today, the world wide anti-infective market exceeds \$20 billion dollars annually and overall antibacterial agents comprise the bulk of this trade. A number of general classes of antibacterial drugs have emerged as mainstays in modern infectious disease chemotherapy (Lorch, 1999; Murray, 1985; Chadwick and Goode, 1997 Chalker, 1995; Lansang, 1990).

Regardless of a better understanding of infectious disease pathogenesis and the importance of sanitation, most individuals will become infected with a microbial pathogen many times, throughout their lives and in developed countries, anti-infective chemotherapy will be periodically administered. Antibacterial amount for the majority of anti-infective agents in comparison to antifungals, antivirals and antiparasitic agents. The concept of antibiotic (against life) substance was put forth by Vuillemin in 1889, but the formal definition as recognized today, would not be introduced until 1942 by Waksman. Thus, antimicrobial such as antibiotics is a chemical substance produced by microorganisms that can inhibit the growth of, or kill other microorganisms (Prescott et al., 2005).

\section{THE PAST}

For about five millennia, give or take a few centuries, human beings have treated their aches and pains with mind-boggling creativity. In 3500
BC, Sumerian physicians treated ailing patients with a beer soup heavily laced with ground snake skins and turtle shells. About 1,500 years later, Assyrian and Babylonian doctors used a salve made of frogs' bile and sour milk for healing infected eyes, but only after the patient took a swig of beer and ate a sliced onion (Magner, 1992). Of course, many ancient remedies had sound scientific foundations. Those same beer-soupdispensing Sumerians knew the value of painkilling opium. The Greeks had a substantial herbbased pharmacopoeia, and the Romans outdid themselves with purgatives. But it wasn't until the mid-19th century that Louis Pasteur observed that some microorganisms could destroy others-a phenomenon Pasteur believed could be useful in medicine. Little did he know (Hoel and Williams, 1997).

The last days of the 19th and the first decades of the 20th centuries saw the birth of aspirin and barbiturates. In 1909, German bacteriologist Paul Ehrlich discovered the first chemical cure for disease-salvarsan, an arsenic compound that cured early syphilis. The medical profession dubbed it "the magic bullet" because it killed the specific germs that caused syphilis.

Next came the era of wonder drugs. In a few short decades, from the 1930s to the late 1960s, medical science discovered antibiotics, sulfa drugs, cortisone, and a stunning collection of other lifesaving medications. Death rates for dozens of diseases plummeted, and medical science won unprecedented victories (Hoel and Williams, 1997).

The golden age of medicine actually began in 1934. That's when Gerhard Domagk, a 38-year-old German pharmacologist, discovered that a dye used to tint cloth seemed to cure streptococcal infections in mice (Robinson, 1976). Domagk's young daughter was dying of a streptococcal infection, and in desperation, he injected the dye into the child. Her fever dropped immediately, and her recovery was nothing short of miraculous.

Next was Daniel Bovert, a Swiss-born scientist, who identified the active compound as sulfanilamide, a white crystalline amide that was deadly to many streptococci and staphylococci. This led to the subduing of pneumonia and a 
number of other bacterial infections. Domagk was awarded the Nobel Prize for Medicine in 1939, but Adolf Hitler forbade him to accept it. Hitler had been outraged because the Nobel Peace Prize for 1935 had gone to an anti-Nazi. He had the gestapo drag Domagk off to prison for a week (Hoel and Williams, 1997).

\section{The Advent of penicillin}

Antibiotics were actually discovered before sulfa drugs, but for 12 years no one showed any interest. In 1928, Alexander Fleming, a shy Scottish bacteriologist, left a culture of staphylococci uncovered in his laboratory at St Mary's Hospital in London while he went off on vacation (Robinson, 1976). When he returned, Fleming noticed mold in the petri dish--along with a sizable vacant space between the staphylococci and the blue-green, spotted mold. As he examined the specimen under his microscope, he noticed that something in the mold was attacking the bacteria. It was the classic instance of what Pasteur had referred to as fortune accommodating a willing mind. Fleming identified the mold as Penicillium notatum, very much like the mold that grows on stale bread. He cultured it in broth, filtered it, and discovered in the filtrate an amazing substance that ravaged bacteria. He named his discovery penicillin (Hoel and Williams, 1997).

Fleming was not able to purify the penicillin himself, and he could not get much help from anyone else. One American university rejected an application for $\$ 100$ to investigate the drug and threatened to fire a professor who offered to pay for research out of his own pocket (Robinson, 1976).

It took the wounded and epidemic-ridden troops and civilians of World War II to awaken the money holders to penicillin's potential. Howard W. Florey, a 42-year-old pathologist from Australia, was given funds to study penicillin at Oxford University. He selected Ernst B. Chain, a 29-yearold chemist who had fled Nazi Germany, to help him. In the spring of 1940, they were able to extract a tiny morsel of a yellowish-brown powder from Fleming's mold. This first sample of penicillin was a million times more powerful than Fleming's original filtrate and, as they say, the rest is history. In 1945, Fleming, Florey, and Chain were awarded the Nobel Prize for Medicine (Hoel and Williams, 1997).

\section{The Emergence of Streptomycin}

Streptomycin hits the stage in 1942, when another great scientist, Selman A. Waksman, a RussianJewish immigrant to the United States, gave the name "antibiotics" to chemicals produced by soilborne fungi and microorganisms that destroy or slow the growth of other microbes. Inspired by the potential of penicillin, Waksman spent his lifetime hunting for friendly microorganisms that would do battle against the unfriendly germs (Hoel and Williams, 1997). When penicillin proved useless for tuberculosis patients, Waksman decided to go after an antibiotic that could quell that ancient scourge. He and his students investigated more than 10,000 soil cultures. Only 1,000 of them destroyed bacteria in preliminary tests, and only 100 of these showed promise in later tests. Just 10 could be isolated, but amazingly one of the 10 carried the mother lode (Hoel and Williams, 1997).

It was 1943 when Waksman's group came across a clump of dirt containing a peculiar mold. The dirt and mold had been taken from the neck of a sick chicken. When Waksman pitted the mold against the feisty tubercle bacilli, the mold won out. He called his discovery streptomycin. Physicians from the Mayo Clinic in Rochester, Minnesota, administered streptomycin to a young woman with advanced pulmonary tuberculosis on November 20, 1944. Her right lung had been removed surgically, and now her remaining lung was being eaten away. The streptomycin saved her life. In less than 10 years, deaths from all forms of tuberculosis in the United States dropped dramatically (Hoel and Williams, 1997).

\section{Lunching in to the possibilities of Antibiotics}

The discoveries of Fleming and Waksman awakened science to the wonders of antibiotics. Soon, more broad-spectrum penicillins and aminoglycosides were found, followed by other landmark antibiotics. Brucellosis, typhoid fever, amebic dysentery, and undulant fever all but disappeared. In these early days, antibiotics were 
often given indiscriminately, sometimes with tragic consequences. Resistant strains developed quickly, and tenacious bugs seemed almost to flaunt their immunity (Hoel and Williams, 1997).

Table 1: Historical Events of Antibiotics

\begin{tabular}{|c|c|}
\hline Date & Major events \\
\hline $\begin{array}{l}1500 \\
\mathrm{BC}\end{array}$ & $\begin{array}{l}\text { Egyptian doctors dispense exotic } \\
\text { concoctions, some of which are based on } \\
\text { sound medical practice. }\end{array}$ \\
\hline $\begin{array}{l}1654- \\
1661\end{array}$ & $\begin{array}{l}\text { When plague strikes, physicians don spice- } \\
\text { filled masks to cover the stench of death. }\end{array}$ \\
\hline $\begin{array}{l}1822- \\
1895\end{array}$ & $\begin{array}{llll}\text { Louis Pasteur recognizes that some } \\
\text { microorganisms destroy others. }\end{array}$ \\
\hline $\begin{array}{l}1928- \\
1940\end{array}$ & $\begin{array}{l}\text { Alexander Fleming discovers penicillin in } \\
1928 \text {, but no one pays much attention until } \\
1940 \text {. }\end{array}$ \\
\hline $\begin{array}{l}1943- \\
1949\end{array}$ & $\begin{array}{l}\text { Antibiotics allow unprecedented victories } \\
\text { over scourges of the past. }\end{array}$ \\
\hline $\begin{array}{l}1950- \\
1969\end{array}$ & $\begin{array}{l}\text { The medical establishments predict an end to } \\
\text { plagues and pestilence. }\end{array}$ \\
\hline $\begin{array}{l}1970- \\
1979\end{array}$ & $\begin{array}{l}\text { New threats, such as Lyme and legionnaires' } \\
\text { diseases, shake up the scene }\end{array}$ \\
\hline $\begin{array}{l}1980- \\
1989\end{array}$ & $\begin{array}{l}\text { Medical science recognizes the mechanisms } \\
\text { and risks of antibiotic resistance. }\end{array}$ \\
\hline $\begin{array}{l}1990- \\
1997\end{array}$ & $\begin{array}{l}\text { Fewer and fewer drugs maintain potency } \\
\text { against rapidly mutating bacteria. }\end{array}$ \\
\hline $\begin{array}{l}1998- \\
2000\end{array}$ & $\begin{array}{l}\text { Bacterial resistance to antibiotics became a } \\
\text { serious medical problem and is of serious } \\
\text { global concern now. Then the advent of } \\
\text { bacteriophage as an alternative to antibiotics } \\
\text { as well as advent of antiretroviral drugs. } \\
\text { A Public health Action Plan to combat } \\
\text { Antimicrobial resistance was established. }\end{array}$ \\
\hline $\begin{array}{l}2001- \\
\text { till } \\
\text { date }\end{array}$ & $\begin{array}{l}\text { Emergence of totally new and stubbornly } \\
\text { obscure infectious agents was not part of the } \\
\text { long-range plan and more drugs are being } \\
\text { discovered in a seemingly inexhaustible } \\
\text { cycle. More Multi-drug resistance as well as } \\
\text { antiretroviral drug resistance among } \\
\text { HIV/AIDS patients. }\end{array}$ \\
\hline
\end{tabular}

According to Meleney (1947), people have to get experience all over again on the behavior of infection under treatment with these new drugs. There is a temptation to use them promiscuously, and yet certainly if results are to be improved, people must use them with discrimination. The next three decades saw exponential growth in pharmaceutical research and manufacturing. Drugs were discovered, diseases were conquered, resistant organisms emerged, and more drugs were discovered in a seemingly inexhaustible cycle. Many of the diseases that had infested the earth for thousands of years were subdued. The medical establishment predicted an end to plagues and pestilence.

\section{THE CURRENT STATUS}

Today some 5,000 antibiotics are known. Only about 1,000 of these have been carefully investigated, and about 100 are currently used to treat infections (Dixon, 1994). Most are produced by actinomycetes molds and bacteria. Throughout the last 50 years, a lot of scientific journals have been disseminating information on drug discovery and evolution. Hundreds of articles on infectious disease management have kept physicians abreast of both advancements and problems. A new vocabulary has emerged: plasmids, transposons, promiscuous DNA, mutator alleles, Cairnsian mutation, and many other esoteric terms. It is a whole new ball game (Hoel and Williams, 1997).

Also, the discovery and development of the betalactam antibiotics are among the most powerful and successful achievements of modern science and technology. Since Fleming's accidental discovery of the penicillin-producing mold, seventy years of steady progress has followed, and today the beta-lactam groups of compounds are the most successful example of natural product application and chemotherapy.

Immediately after the penicillin production by Penicillium chrysogenum came the discoveries of cephalosporin formation by Cephalosporium acremonium, Cephamycin, Clavam and Carbapenem production by actinomycetes, and monocyclic beta-lactam production by actinomycetes and unicellular bacteria. Each one of these groups has yielded medically-useful products and has contributed to the reduction of pain and suffering of people throughout the world. Research on the microbiology, biochemistry, genetics and chemistry of these compounds have continued up to the present with major contributions being made by both individual and collaborative groups from industry and academia (Demain and Elender, 1999).

According to Demain and Elender (1999), the 
discovery of penicillin not only led to the era of the wonder drugs but provided the most important antibiotics available to medicine. Continued efforts have resulted in the improvement of these compounds with respect to potency, breadth of spectrum, activity against resistant pathogens, stability and pharmacokinetic properties. Major advances are being made on structural and regulatory biosynthetic genes and metabolic engineering of the pathways involved on the research front.

Presently, new semi synthetic compounds especially those designed to combat resistance development are being examined in the clinic, and unusual non-antibiotic activities of these compounds are being pursued. Although seventy years of age, the beta-lactams are not yet ready for retirement. Approximately half of the world's antibiotic production is not used as human medicine but for animals. Some antibiotics for industrialized husbandry are sold freely over the counter as growth promoters. Several of these antibiotics are known for cross-resistance to those used in human medicine. It has been shown that antibiotic resistant bacteria are present in meat products and can also be found in humans who have not received these substances in the course of a medical treatment (Davies, 1994; Lansang, 1990; Jacoby, et. al., 1991, Murray, 1985). Although so far there is no evidence for a causal relationship, this potential spread of resistance adds to the problems with antibiotics for future medical applications (Lorch, 1999).

\section{The Onset of Antimicrobial Resistance}

Bacterial resistance to antibiotics has become a serious medical problem and is of serious concern now (Lorch, 1999). Just a decade or two ago, Lyme disease, toxic shock syndrome, legionnaires' disease, Ebola and Marburg viruses, Lassa fever, hepatitis C, hantavirus, and of course HIV/AIDS startled scientists and physicians lulled by the successes of the past. Emergence of totally new and stubbornly obscure infectious agents was not part of the long-range plan. Resources, limited as they were, had been directed elsewhere. Many experts felt hopelessly ill-prepared for the future (Hoel and Williams, 1997).
According to Appelbaum (2005), clinical resistance to penicillin in Streptococcus pneumoniae was first reported by researchers in Boston in 1965; subsequently, this phenomenon was reported from Australia (1967) and South Africa (1977). Since these early reports, penicillin resistance has been encountered with increasing frequency in strains of S. pneumoniae from around the world. In South Africa strains resistant to penicillin and chloramphenicol as well as multiresistant strains have been isolated. Similar patterns of resistance have been reported from Spain. Preliminary evidence points to a high prevalence of resistant pneumococci in Hungary, other countries of Eastern Europe, and some countries in other areas of Europe, notably France. In the United States most reports of resistant pneumococci come from Alaska and the South, but resistance is increasing in other states and in Canada. Pneumococcal resistance has also been described in Zambia, Japan, Malaysia, Pakistan, Bangladesh, Chile, and Brazil; information from other African, Asian, and South American countries is not available.

The onset of drug resistance however threatens virtually all classes of antibacterial agents. Resistant bacteria have been known virtually since modern antibacterial chemotherapy became an accepted medical practice. Only a few years after the penicillin's were introduced, resistant staphylococci (S. aureus) were recognized. Since this time (1944), most Staphylococci have acquired resistance to conventional penicillin's and many Streptococci have followed this trend (Davies, 1994; Murray, 1985; Macaden, 1985; Wenzel, 1995; Prescott et al., 2005).

However since the 1980's, there has been a complacency regarding antibacterial chemotherapy; many believed that humanity had forever gained 'the upper hand' in the battle against microbes. The past decade alone has been a very alarming 'wake-up' to battle once again; the emergence of a resistant and exceptionally virulent bacterial strains are once again causing outbreaks and deaths, and unfortunately, this trend is likely to continue except for the advent of phage therapy (Lorch, 1999). 
All over the world, the resistance of bacteria to antibiotics is becoming a grave medical problem. Independent of the resources of the medical system, whenever antibiotics are used the development of resistance is a logical consequence; like all other living organisms, bacteria adapt to changing environmental conditions in a continuous process of evolution (Lorch, 1999). In industrialized countries, bacteria are developing multiple resistances to a range of antibiotics, which threatens to make the achievements of modern medicine futile (Lorch, 1999). Without the protection against bacterial infections, for instance, large-scale operations and treatments that weaken the patients' immune system, such as chemotherapy or organ transplantation, would not be possible (Lorch, 1999). In developing countries basic medical care is already endangered by single resistance to inexpensive common generic antibiotics.

According to the World Health Organization report (WHO, 1993, 1999), a great number of the population of developing countries will not be able to afford the replacements. In these countries, dosage often appears to be too low or treatment is not carried out over the whole course; resistance is encouraged because even if the patient is cured, those bacteria that are best adapted to low doses of these antibiotics survive. Cases of reported antibiotic resistance comprise tuberculosis, pneumonia and dysentery (World bank, 1995; Lorch, 1999).

Although the spread of antibiotic resistance has long been known as a worldwide phenomenon, research seems to have reached a dead end. During the last 30 years, no new classes of antibiotics have been found, even with the help of modern biotechnology such as genetic engineering (Prescott et al., 2005). Pharmaceutical companies have mainly focused on the development of new products derived from the known classes of antibiotics. The spread of drug resistant pathogens is one of the most serious threats to the successful treatment of microbial disease.

Welch (1984), writing in the November 1, issue of Postgraduate Medicine, of the US Public Health Service, based in Bethel, Alaska, addressed the problems of antibiotic resistance. He also provided an explanation of plasmid exchange as a cause of the epidemic of drug failure. As he pointed practitioners toward the future, Welch (1984) stated that the microbiologist views antimicrobial prescribing as excessive and particularly implicates empiric and prophylactic therapy. The clinician feels that the benefits of early therapy and of antibiotic prophylaxis are underrated by basic science colleagues. The microbiologist necessarily takes the long-term view (the prospect of multiple resistance), while the clinician is more concerned with the short-term effect (the patient's immediate welfare). Unless these two views are reconciled, plasmid epidemics will become common place.

Along with the new threats, some of the old scourges of humankind were reemerging in the 1980s. Under funded prevention programs and drug resistance were allowing diseases like yellow fever, cholera, malaria, bacterial meningitis, dengue fever, tuberculosis, and even plague to spring back with renewed vengeance. By the early 1990s, panicky investigators were realizing they had very few resources to combat these stronger, smarter foes (Welch, 1984; Hoel and Williams, 1997).

According to Hagman, and Strausbaugh, (1996), in the May issue of Postgraduate Medicine, of Oregon Health Sciences University in Portland, sounded yet another alert. They pointed out that the antibiotic arsenal is dwindling quickly. Specifically, vancomycin, generally considered the last stronghold against many lifethreatening gram-positive infections, is losing ground. While discussing vancomycin-resistant enterococci, Hagman and Strausbaugh (1996), warn that new antimicrobial pathogens resistant to vancomycin are wreaking havoc in medical centers throughout the nation. Their tendency to colonize or infect severely ill, hospitalized patients who have undergone invasive procedures and received prolonged courses of antimicrobial therapy is alarming. The most potent weapon in the physician's arsenal against these enemies is familiarity with their key features, with the guidelines for prudent use of drug therapy, and with the precautionary measures necessary to limit contact and spread (Hoel and Williams, 1997). 


\section{Mechanism of the Antimicrobial Resistance}

Bacteria become drug resistant in several ways. It should be noticed at the beginning that a particular type of mechanism is not confined to a single class of drugs. Two bacteria may use different resistant mechanism to withstand the same chemotherapeutic agent (Prescott et. al., 2005, Jacoby et al., 1991). Furthermore, resistant mutants arise spontaneously and are then selected. Mutants are not created directly by exposure to a drug. According to Strohi (1997) and Prescott et al. (2005), Pathogens often become resistant simply:

a. By preventing entrance of the drug into the envelope's membrane.

b. By pumping the drug out of the membrane after it has entered (translocases).

c. By inactivating drugs through chemical modification (hydrolysis).

d. By modification of target enzyme or organelle so that is no longer susceptible to the drug.

e. They may either use an alternate pathway to bypass the sequence inhibited by the agent or increase the production of target metabolite.

\section{The Origin of Drug Resistance and Its Transmission}

Ironically, resistance is promoted by both the overuse of antibiotics as well as insufficiency of dose (Lansang, 1990, WHO, 1993, 1999; Chalker, 1995; World Bank, 1995). The gene for drugs resistant are present as both the bacteria chromosome and plasmids, small circular DNA molecules that can exist separate from the chromosome or be integrated into it. Also, spontaneous mutations will make bacteria drug resistant (Chadwick and Goode, 1997).

Frequently, a bacteria pathogen is drug resistant because it has a plasmid bearing one or more resistant genes, such plasmids are called Rplasmids. They often code for enzymes that destroy or mortify drugs. Once a bacterial cell process an R-plasmid, the plasmid may be transferred to other cells quite rapidly through normal gene exchange processes, such as conjugation, transduction and transformation (Prescott et al., 2005).

Extensive drug treatment favors the development and spread of antibiotic resistant strains because the antibiotic destroys normal, susceptible bacteria that would usually compete with drug resistant strains (Chadwick and Goode, 1997). The result may be the emergence of drug resistant pathogens leading to a super-injection. A possible effective alternative way of combating these resistance mechanisms is that of phage therapies, which are, viruses that live on bacteria and this offer a better advantages (Lorch, 1999). The goal of antibiotics in disease such as gastroenteritis is to decrease stool water and electrolyte losses, thus limiting the morbidity resulting from dehydration. To date, several drugs have been tried in the treatment of acute diarrhea but none has met the requirements enumerated above. They are therefore of very limited value in the department of diarrhea, especially in children (Strohi, 1997; Prescott et al., 2005). It is time for a new game plan.

\section{Trends in Antimicrobial Resistance}

According to White et al. (1999) antibioticresistant pathogens in animals pose a concern not only with respect to the health of animals but because of possible transmission to humans as food-borne pathogens. The problem is compounded by the growing number of pathogens that are resistant to multiple, structurally unrelated drugs, leading to the concern that there are likely to be few effective antimicrobials available by the end of the decade. Accordingly, more attention is now being paid to the ease with which resistance to both single and multiple antimicrobials can develop among bacterial pathogens. If the current trends continue, we may see bacterial pathogens that are resistant to all currently available antimicrobials. The Food and Drug Administration and the United States Department of Agriculture are currently implementing strategies to address this threat.

In the past few years, strains of E. coli have become increasingly resistant to most first-line antibiotics, including third-generation cephalosporins, aminoglycosides, and even fluoroquinolones. Infections caused by drugresistant organisms are a major and costly problem in animal health. These infections prolong illness 
and, if not treated in time with more expensive, alternative antimicrobial agents, can cause loss of stock. This potential problem will continue to be scourge and have a large impact on the animal industry and humans, across the countries of the world if not investigated and solved.

For instance, in a study by White et al. (1999) on the prevalence of multiple-antibiotic resistance among E. coli strains implicated in bovine calf scours in North Dakota was determined by studying E. coli isolates from scouring calves, they hoped to identify trends in antibiotic resistance and to track several virulence factors that have recently been identified in pathogenic E. coli strains. Susceptibility testing for amikacin, ampicillin, ceftiofur (Naxcel; Upjohn, Kalamazoo, MI), gentamicin, tetracycline, sulfachlorpyridazine (Vetisulid; Solvay Animal Health, Mendota Heights, MN), sulfonamides, enrofloxacin (Baytril; Miles Animal Health, Shawnee Mission, KS), lincomycin, neomycin, spectinomycin, and trimethoprim/sulfadiazine (Tribissen; Mallinckrodt Veterinary, Mundelein, IL) was performed using standard disk-diffusion assays. E. coli strains are screened for several virulence factors: F-5 (K-99) fimbriae, enterotoxin genes (lt, sta, stb), shiga-like toxins (slt-I, slt-II), enterohemolysin gene (Ehly), the E. coli attaching and effacing gene (eae), cytotoxic necrotizing factor genes (cnf-I, cnf-II), and cs31a, a fimbriae gene.

The result of their study showed that more than 280 isolates of E. coli, obtained from clinical cases, submitted to the North Dakota State University Veterinary Diagnostic Laboratory in 1996. The resulting antibiograms of antibiotic susceptibilities have illustrated patterns of resistance among the strains and changes in resistance over time. Preliminary results show that resistance to fluoroquinolones (enrofloxacin, which currently is not approved for use in large animals) and to cephalosporins (ceftiofur) are emerging among these E. coli strains. The level of resistance to the antimicrobials tested ranged from less than $1 \%$ of isolates to $100 \%$ of submitted strains. Eighteen of the 280 strains were positive for enterohemolysin and were further characterized by polymerase chain reaction for virulence factors previously reported to be involved in pathogenesis. All 18 strains were negative for $1 \mathrm{t}$, sta, and stb. Six strains were positive for slt-I, five were positive for slt-II, and three strains were positive for slt-I and slt-II. Four strains were positive for eae, and five strains carried the cs31a fimbriae gene. Although the K99 antigen was found in $56 \%$ of strains, none of the strains positive for enterohemolysin expressed this antigen. Four strains were positive for cnf-I, and one strain was positive for cnf-2. Two strains were positive for slt-II and cnf-I, and one strain was positive for sit-I and cnf-I. All strains positive for slt-I and slt-II were also positive for shiga-like toxins production.

According to him, isolates submitted to their laboratory are usually the "worst of the worse," being unresponsive to all other treatments. Their testing showed that the most available drugs have the highest rates of bacterial resistance. Unfortunately, these drugs are often the first line of defense in combating calf scours. Amikacin, enrofloxicin, or ceftiofur continue to be effective and with electrolyte fluid therapy constitute the best treatment options for calf scours at the present time. However, enrofloxacin is not approved for large animal use; amikacin and ceftiofur are only approved for extra-label use.

\section{THE FUTURE}

While we are been reminded daily how quickly disease can spread from jungles to urban centers, at present there is virtually no way to predict what will happen where. According to Lemonick (1996), in a recent article on emerging infection that appeared in a special edition of Time, the challenge for the near future undoubtedly lies in quickly identifying and isolating outbreaks and limiting damages. Lemonick (1996) states that it is guerrilla warfare, but for the next few years at least, it may be the best we can do (Hoel and Williams, 1997). Morse (1996), head of the infectious disease program at Columbia University, adds that the current system is a reactive one. Our ability for prediction will remain limited for quite some time.

Garrett (1994), in her riveting and frightening book, the Coming Plague: Newly Emerging Diseases in a World out of Balance recounts some 
of the recent disease outbreaks that have triggered dramatic attention around the world. From the mysterious outbreak of Bolivian hemorrhagic fever in 1962 to the recent Reston Ebola scare, Garrett narrates the sequence of events she believes will become more common as new and more virulent microbes surface (Hoel and Williams, 1997).

As Garrett (1994) presents her case, she talks about the "soupy existence" of microbes stating that wherever there may be an ideal soup for a microbe, it will eagerly take hold, immediately joining in the local microbial pushing-andshoving. The most sophisticated of their species have the ability to outwit or manipulate the one microbial sensing system Homo sapiens possess, that is, our immune systems. By sheer force of numbers they overwhelm us. And they are evolving far more rapidly than Homo sapiens, adapting to changes in their environments by mutating, undergoing high-speed natural selection, or drawing plasmids and transposons from the vast mobile genetic lending library in their environments (Hoel and Williams, 1997).

\section{What is the next line of Action?}

From many literatures cited in this review, we strongly suggest that resistance to first-line antibiotics/antiretroviral used for many infectious diseases is emerging at an alarming rate. Multidrug resistance and the presence of several virulence factors in the strains of many pathogens responsible for different diseases pose an increasing threat to the successful management of disease scourge. Also, the rising prevalence of drug resistance such as penicillin-resistant pneumococci worldwide mandates selective susceptibility testing and epidemiological investigations during outbreaks (Appelbaum, 2005).

According to many authors, the time for action is now. What can physicians, health workers and NGOs do to improve this picture? Primary prevention and disease containment are crucial steps, according to many experts. Sex might be a good place to start as suggested by Garrett (1994), pointing to limited but nonetheless encouraging results with sex education programs for
HIV/AIDS, Chlamydial infections, and other sexually transmitted diseases (STDs). Programs to provide sterile needles to drug users certainly seem likely to be effective, if controversial, alternatives to spreading disease through needle sharing. Improved surveillance and strictly enforced protocols for preventing spread of infections in hospitals and clinics are also extremely important. And, of course, judicious use of antibiotics is crucial, including veterinary and farming applications (Hoel and Williams, 1997).

Much as we might hate to admit it, antibiotics/antiretroviral have been over prescribed and sometimes provided on demand, greatly diminishing the strength of the arsenal. Patient education about judicious use of drugs, about not sharing antibiotics, and about compliance should be a regular part of physicians' instructions to the patients. According to Hoel and Williams (1997), a small but extremely important step for a practicing physician might be the simple practice of using and teaching patients to use proper hand washing as a means of slowing down the spread of disease.

A better understanding of the true problem is also at the top of the list of what needs to be achieved next as pointed out by Osterholm (1996). Minnesota state epidemiologist Osterholm (1996) assisted the Centers for Disease Control and Prevention (CDC) in surveying the policies and capability of all 50 state health departments. The survey showed that after years of budget cuts, most local and regional disease reporting systems were sadly deficient, if not completely unreliable. Unusual deaths were going unreported. Contagious outbreaks were ignored. The incidence of HIV/AIDS was underreported by at least $20 \%$ at any given time. Officials could only guess about the real incidences of penicillin-resistant gonorrhea and vancomycin resistant enterococcus, E coli food poisoning, multiple-drug resistant tuberculosis, Lyme disease, and many other problems. When the CDC asked that reporting be expanded, there were loud protests. Local health departments simply can not keep up with what they are already required to do (Hoel and Williams, 1997).

The national, international and global 
situations are also disheartening. Laboratories continue to be sadly behind the times in terms of equipment and skills for diagnosing the emerging pathogens as can be readily observed in this nation-Nigeria. With the overwhelming increase in high-intensity local conflicts among political, ethnic, and religious rivals, government-based disease-surveillance systems have little or no chance of success.

According to Ogundipe et al. (1989), in their study the development and efficiency of the animal health information system in Nigeria as well as the completeness and immediacy of data supply by the system for the period between January 1977 and December 1984 revealed that the system was found to be characterized by: late, inaccurate and gross under reporting. And these constraints in reporting include inadequate personnel, poor diagnostic and reporting facilities.

Some steps are being taken. The worldwide communications networks have made inroads with SatelLife and ProMED online services. Physicians in developing nations can consult colleagues, libraries, or data banks for help with puzzling cases. Promising as they are, though, these "electronic conference tables" represent only a small piece of the solution. At present, the networks do not address the underlying causes of new and reemerging infectious diseases. And they probably can do little to get to the heart of the real issues: educating the public, immunizing the children, improving sanitation, cleaning up the water, housing the homeless, feeding the starving (Hoel and Williams, 1997).

For now, as Lemonick (1996) points out that the best that health professionals can hope to do is react quickly to an endlessly resourceful, sneaky, and relentless enemy as well as the ability to recognize that a successful holding action is the next best thing to victory.

The health care workers must recognize the pivotal role they play in our national notifiable disease system. The system breaks down if any one step, such as appropriate diagnostic testing, reporting by health care workers to public health agencies, or follow-up investigation, is not accomplished. In addition, we can not stress strongly enough how important it is to report unusual or puzzling outbreaks of infectious diseases (Berkelman (1997; Hoel and Williams, 1997).

According to the WHO (1999) in developing countries infections and parasitic diseases are responsible for the death of twenty million people per year. Every year about eight million children under five die of acute respiratory tract infections of bacteria such as Streptococcus pneumonia, Haemophilus influenza type B or of diarrhea related diseases caused by bacteria such as Shigella sp., Vibrio cholera and several types of $E$. coli ( Lorch, 1999; Macalden, 1985).

In Africa, dysentery caused by Shigella dysenteriae is common. Since the late 1970s, drug-resistant strains of $S$. dysenteriae have caused epidemics in various parts of Central and Southern Africa. By 1990, several of these epidemics were caused by strains resistant to all antibiotics used in those countries. The availability of advanced antibiotics is often limited by their higher costs (Lorch, 1999; Macalden, 1985).

The situation in developing countries like Nigeria has not really improved during the past decade, state and local support for infectious disease surveillance has diminished because of budget restrictions. For example, until recently a number of states had no foodborne disease surveillance programs despite dramatic evidence that disease caused by contaminated food may be increasing. Moreover, there has been little or no federal support to states for the notifiable disease surveillance system, and many state health laboratories receive no federal funding.

In developed countries, this picture is beginning to change. The CDC has already taken steps needed to implement a preventive strategy. Over 15 states are strengthening their infectious disease programs, and five more are establishing such programs in addition to the effort of the CDC (Berkelman, 1997; Hoel and Williams, 1997). Though, Berkelman (1997) stresses that while the debate on healthcare reform has focused intensely on providing individual medical care; discussions have not adequately addressed the equally important topic of public health concern. The costs of preparedness through vigilance are far lower than those needed to respond to unanticipated 
public health crises.

\section{Public Health Action Plan to Combat Antimicrobial Resistance}

When it comes to keeping an eye on emerging diseases, agencies of the Centers for Disease Control and Prevention (CDC) are on the front lines. According to Berkelman (1997), we once believed we could eliminate infectious diseases as public health problems but the emergence of HIV/AIDS, the resurgence of tuberculosis, and the specter of increasing antimicrobial resistance have raised new challenges. Still, we have learned a lot in the last few years about what it will take to get the job done.

This Public Health Action Plan to Combat Antimicrobial Resistance (Action Plan) was developed by an interagency Task Force on Antimicrobial Resistance that was created in 1999. The Task Force is co-chaired by the Centers for Disease Control and Prevention, the Food and Drug Administration, and the National Institutes of Health and also includes the Agency for Healthcare Research and Quality, the Health Care Financing Administration, the Health Resources and Services Administration, the Department of Agriculture, the Department of Defense, the Department of Veterans Affairs, and the Environmental Protection Agency. The Action Plan reflects a broad-based consensus of federal agencies on actions needed to address antimicrobial (a) resistance (AR). Input from state and local health agencies, universities, professional societies, pharmaceutical companies, health care delivery organizations, agricultural producers, consumer groups, and other members of the public was important in developing the plan. While some actions are already underway, complete implementation of this plan will require close collaboration with all of these partners ( $\underline{b})$, a major objective of the process. The plan will be implemented incrementally, dependent on the availability of resources.

The Action Plan provides a blueprint for specific, coordinated federal actions to address the emerging threat of antimicrobial resistance. This document is Part I of the Action Plan, focusing on domestic issues. Since AR transcends national borders and requires a global approach to its prevention and control, Part II of the plan, to be developed subsequently, will identify actions that more specifically address international issues. The Action Plan, Part I (Domestic Issues), includes four focus areas: Surveillance, Prevention and Control, Research, and Product Development. A summary of the top priority goals and action items in each focus area follows: Surveillance, Prevention and control, Research, as well as Product development.

\section{Surveillance}

Unless AR problems are detected as they emerge and actions are taken quickly to contain them the world may soon be faced with previously treatable diseases that have again become untreatable, as in the pre-antibiotic era. Priority Goals and Action Items in this focus area address ways to: Develop and implement a coordinated national plan for AR surveillance; Ensure the availability of reliable drug susceptibility data for surveillance; Monitor patterns of antimicrobial drug use; and Monitor AR in agricultural settings to protect the public's health by ensuring a safe food supply as well as animal and plant health.

A coordinated national surveillance plan for monitoring $\mathrm{AR}$ in microorganisms that pose a threat to public health will be developed and implemented. The plan will specify activities to be conducted at national, state, and local levels; define the roles of participants; promote the use of standardized methods; and provide for timely dissemination of data to interested parties, e.g., public health officials, clinicians, and researchers. Needed core capacities at state and local levels will be defined and supported. When possible, the plan will coordinate, integrate, and build on existing disease surveillance infrastructure. All surveillance activities will be conducted with respect for patient and institutional confidentiality.

The availability of reliable drug susceptibility data is essential for AR surveillance. The accuracy of AR detection and reporting will be improved through training and proficiency testing programs for diagnostic laboratories and by 
promoting and further refining standardized methods for detecting drug resistance in important pathogens, including bacteria, parasites, fungi, and viruses. Public and private sector partners will address barriers to AR testing and reporting, e.g., barriers due to changes in health care delivery.

A plan to monitor patterns of antimicrobial drug use will be developed and implemented as an important component of the national $A R$ surveillance plan. This information is essential to interpret trends and variations in rates of $\mathrm{AR}$, improve our understanding of the relationship between drug use and resistance, identify and anticipate gaps in availability of existing drugs, and identify interventions to prevent and control AR.

Improved surveillance for $A R$ in agricultural settings will allow early detection of resistance trends in pathogens that pose a risk to animal and plant health, as well as in bacteria that enter the food supply. Agricultural surveillance data will also help improve understanding of the relationship between antimicrobial drug and pesticide use and the emergence of drug resistance.

\section{Prevention and Control of Antimicrobial Resistance (AR)}

The prevention and control of drug-resistant infections requires measures to promote the appropriate use (c) of antimicrobial drugs and prevent the transmission of infections (whether drug-resistant or not). Priority Goals and Action Items in this focus area address ways to: Extend the useful life of antimicrobial drugs through appropriate use policies that discourage overuse and misuse; Improve diagnostic testing practices; Prevent infection transmission through improved infection control methods and use of vaccines; Prevent and control emerging AR problems in agriculture, human and veterinary medicine; and Ensure that comprehensive programs to prevent and control AR involve a wide variety of nonfederal partners and the public so these programs become a part of routine practice nationwide.
Appropriate drug-use policies will be implemented through a public health education campaign on appropriate antimicrobial drug use as a national health priority. Other actions in support of appropriate drug use will include reducing inappropriate prescribing through development of clinical guidelines and computer-assisted decision support, considering regulatory changes, supporting other interventions promoting education and behavior change among clinicians, and informing consumers about the uses and limitations of antimicrobial drugs.

Improved diagnostic practices will be promoted by encouraging the use of rapid diagnostic methods to guide drug prescribing, facilitating direct consultation between clinicians and laboratory personnel with appropriate expertise and authority, and promoting the use of appropriate laboratory testing methods. Guidelines, training, and regulatory and reimbursement policies will be utilized to promote improved diagnostic practices.

Reduced rates of infection transmission will be addressed through public health campaigns that promote vaccination and hygienic practices such as hand washing, safe food handling, and other behaviors associated with prevention of infection transmission. Infection control in health care settings will be enhanced by developing new interventions based on rapid diagnosis, improved understanding of the factors that promote crossinfection, and modified medical devices or procedures that reduce the risk of infection.

The prevention and control of $A R$ in agriculture and veterinary medicine requires 1) improved understanding of the risks and benefits of antimicrobial use and ways to prevent the emergence and spread of resistance; 2) development and implementation of principles for appropriate antimicrobial drug use in the production of food animals and plants; 3) improved animal husbandry and food-production practices to reduce the spread of infection; and 4) a regulatory framework to address the need for antimicrobial drug use in agriculture and 
veterinary medicine while ensuring that such use does not pose a risk to human health.

\section{Comprehensive, multifaceted programs} involving a wide variety of nonfederal partners and the public are required to prevent and control AR. The AR Task Force agencies will ensure ongoing input from, review by, and collaboration with nonfederal partners. The appropriate agencies will support demonstration projects that use multiple interventions to prevent and control AR (e.g., through surveillance, appropriate drug use, optimized diagnostic testing, immunization practice, and infection control). The Task Force agencies will encourage the incorporation of effective programs into routine practice by implementing model programs in federal health care systems and promoting the inclusion of AR prevention and control activities as part of quality assurance and accreditation standards for health care delivery nationwide.

\section{Research}

Understanding the fundamental processes involved in antimicrobial resistance within microbes and the resulting impact on humans, animals, and the environment forms an important basis for influencing and changing these processes and outcomes. Basic and clinical research provides the fundamental knowledge necessary to develop appropriate responses to antimicrobial resistance emerging and spreading in hospitals, communities, farms, and the food supply. Priority Goals and Action Items in this focus area address ways to: Increase understanding of microbial physiology, ecology, genetics and mechanisms of resistance; Augment the existing research infrastructure to support a critical mass of researchers in AR and related fields; and Translate research findings into clinically useful products, such as novel approaches to detecting, preventing, and treating antimicrobial resistant infections.

Needs in the field of $A R$ research will be identified and addressed through a governmentwide program review with external input. Additional research is needed, for example, on the epidemiology of resistance genes; on mechanisms of AR emergence, acquisition, spread, and persistence; and on the effects of antibiotics used as agricultural growth promotants on microbes that live in animals, humans, plants, soil and water. Further study is also required to determine whether variations in drug use regimens may stimulate or reduce AR emergence and spread. Improved understanding of the causes of AR emergence will lead to the development of tools for reducing microbial resistance, as well as for predicting where AR problems are likely to arise.

A comprehensive research infrastructure will help ensure a critical mass of AR researchers who will interact, exchange information, and stimulate new discoveries. This aim will be achieved through the appropriate strategies and scientific conferences that promote research on AR. The AR Task Force agencies will work with the academic and industrial research communities to attract AR researchers, prioritize needs, identify key opportunities, and optimize the utilization of resources to address AR problems.

The translation of research findings into innovative clinical products to treat, prevent, or diagnose drug-resistant infections is an area in which the federal government can play an important role, focusing on gaps not filled by the pharmaceutical industry or by other nongovernment groups. Special efforts will be placed on the identification, development and testing of rapid, inexpensive, point-of-care diagnostic methods to facilitate appropriate use of antimicrobials. The AR Task Force agencies will also encourage basic research and clinical testing of diagnostic methods, novel treatment approaches, new vaccines, and other prevention approaches for resistant infections.

\section{Product Development}

As antimicrobial drugs lose their effectiveness, new products must be developed to prevent, rapidly diagnose, and treat infections. The Priority Goals and Action Items in this focus area address ways to: Ensure that researchers and drug manufacturers are informed of current and projected gaps in the arsenal of antimicrobial 
drugs, vaccines, and diagnostics and of potential markets for these products (designated here as "AR products"); Stimulate the development of priority AR products for which market incentives are inadequate, while fostering their appropriate use; and Optimize the development and use of veterinary drugs and related agricultural products that reduce the transfer of resistance to pathogens that can infect humans.

Current and projected gaps in the arsenal of AR products and potential markets for these products will be reported to researchers and drug manufacturers through an interagency working group convened to identify and publicize priority public health needs.

The development of urgently needed AR products will be stimulated throughout the process from drug discovery through licensing. The regulatory process for AR products will continue to be streamlined, and incentives that promote the production and appropriate use of priority AR products can be evaluated in pilot programs that monitor costs and assess the return on the public investment.

The production of veterinary AR products that reduce the risk of development and transfer of resistance to drugs used in human clinical medicine will be expedited through a streamlined regulatory and approval process. As with drugs for the treatment of human infections, pilot programs can be initiated to evaluate incentives that encourage the development and appropriate use of priority products that meet critical animal and plant health needs. Private and public partners will also evaluate ways to improve or reduce the agricultural use of particular antimicrobial drugs, as well as ways to prevent infection, such as the use of veterinary vaccines, changes in animal husbandry, and the use of competitive exclusion products (i.e., treatments that affect the intestinal flora of food animals).

\section{Biotechnology's promises}

In recent years, bacteriology has been greatly expanded from its concentration on diseasecausing pathogens. Escherichia coli, a normal inhabitant of the human intestinal tract, is the most thoroughly studied of all organisms. Studies of the mechanisms of genetic exchange and the biology of plasmids and bacteriophages of $E$. coli have been crucial in understanding many aspects of DNA replication and the expression of genetic material. These studies have led to the ability to insert DNA from unrelated organisms into $E$. coli plasmids and bacteriophages, and to have that DNA replicated by the bacteria, with the genetic information it contains expressed by the bacteria (Dimmock et. al., 1993; Karam, 1994; Prusiner, 1996; Prescott et. al., 2005).

In recent biotechnology development, DNA analysis is assisting with precise identification of outbreaks and with rapid diagnosis of new cases. Molecular biology breakthroughs allow identification and tracking of organisms so surveillance teams can quickly link related cases. Genetic engineering is helping us understand how resistance takes hold and what might be done to suppress it.

However, new antibiotics have been developed recently, including some that are effective against $S$. pneumoniae and vancomycinresistant organisms. The threat of epidemics has triggered unprecedented Cooperation among scientists, government agencies, physicians, and drug manufacturers. Fast-track research is encouraging development of critically needed therapeutic agents. Still, the cost of bringing a new antibiotic from discovery to market (estimated at between $\$ 100$ million and $\$ 350$ million for the United States) is a serious concern for the manufacturers who must recoup their investment (Gold and Moellering, 1996; Hoel and Williams, 1997).

According to Benjamin Schwartz, MD, Chief of the CDC's Childhood and Vaccine Preventable Diseases Section, Division of Bacterial and Mycotic Diseases in a recent report by Hoel and Williams (1997) said that Primary care health care workers will also play a critical role in controlling antibiotic resistance in the future. Health care workers can help a great deal by closely monitoring how antibiotics are used. Cutting back on the 50 million or so courses of unnecessary antibiotic therapy prescribed each year will have a 
major effect on slowing down the development of resistance. And that culturing infectious organisms and testing for sensitivity also are crucial for controlling resistance. The primary health care workers can help bring the problem under control though everyone is trying to keep costs down, but eliminating lab tests for antibiotic sensitivity will only cause more problems and cost more money in the long run.

Improved awareness is leading, slowly but surely, to an appreciation of what meaningful prevention programs should include and what they will cost. There is a subtle and tentative resurgence of confidence in our ability to wrestle control over our microbial future. But for those of us on the front lines of disease management, vigilance continues to be the watchword. Our individual small steps can make a difference as revealed by Hoel and Williams (1997).

Although, in recent time, World Health Organization (WHO) and AIDS Prevention Initiative in Nigeria (APIN) of Harvard University in collaboration with the Federal Ministry of Health have really intensified on their front line of disease surveillance and disease management in Nigeria as in the case of Polio eradication programme and HIV/AIDS prevention programme but the inadequate availability of diagnostic facilities and competent personnel in some part of the country could result in considerable time being lost before outbreak or reemergence of antimicrobial resistant pathogens as well as notifiable diseases is confirmed and reported.

There is therefore an urgent need to improve the use of antibiotics and the medical system by adopting the various recommendations already made. It must be noted that improvement in diagnostic and diseases reporting facilities as recommended will really help in the resurgence of confidence in our ability to wrestle control over our microbial future. It is our hope that this review will stimulate the examination of antibiotic resistance in some of the states that are lagging behind as this bacterial resistance to antibiotics has become a serious medical problem of global concern now.

\section{REFERENCES}

Chadwick, D.J. and Goode, J. 1997. Antibiotic resistance: Origins, evolution, selection and spread. Ciba Foundation symposium. Chister, UK: John Wiley \& Sons. 207:1-10

Chalker, J. 1995. Effect of a drug supply and cost sharing system on prescribing patterns and on utilization of health facilities, a controlled trial from heath posts in the hills of Nepal. Health policy and planning. 10 (4):423-430

Davies, J. 1994. Inactivation and the dissemination of resistance genes. Science 264: 375-82

Demain, A.L. and Elander, R. P. .1999. The betalactam antibiotics: past, present, and future.

Antonie Van Leeuwenhoek.75(1-2):5-19.

Dimmock, N.J. and Primrose, S.B. 1993. An Introduction to Modern Virology, $4^{\text {th }}$ edition. Blackwell, Oxford. Pp 564.

Dixon, B. 1994. Power unseen: how microbes rule the world. New York: WH Freeman.

Garrett, L. 1994. The coming plague: newly emerging diseases in a world out of balance. New York: Penguin Books.

Gold, H.S. and Moellering, R.C. Jr.1996. Antimicrobial-drug resistance. N. Engl J Med; 335(19):1445-53

Hagman, H.M. and Strausbaugh, L.J. 1996. Vancomycin-resistant enterococci: the 'superbug' scourge that's coming your way. Postgrad. Med; 99(5):62-71

Hoel, D. and Williams, D. N. 1997. Antibiotics: Past, present, and future-Unearthing nature's

magic bullets. Postgraduate Medicine, Vol 101:1 January 1997

Holzman, D. (1998). Phage as antibacterial tool. Genetic Engineering News. 15 October, pp48.

Jacoby, G.A., and Archer, G.L. 1991. New mechanisms of bacterial resistance to

antimicrobial agents. New England Journal of Medicine, 324 (9): 601-9.

Karam, J.D. 1994. Molecular biology of bacteriophage T4. Herridon, Va: ASM Press

Knudson, M., 1998. The Hunt is on: For New Ways to Overcome Bacterial Resistance novel antibiotics and phage therapy as answers to this problem IACFA Newsletter: May, Issue 52. Reprinted from $M I T^{\prime}$ 's Technology Review on the mechanism of antibiotic resistance Jan/Feb 1998, Vol 100:9

Lansang, M. 1990. Purchase of antibiotics without prescription in Manila, the Philippines, in appropriate choices and doses, Journal of Clinical Epidemiology 
43:61-67

Lemonick, M.D. 1996. Guerrilla warfare. Time. Fall Special Issue: 59, 62

Levy, S.B. 1995. Antimicrobial resistance, a global perspective in Antimicrobial resistance, a Crisis in Health care, Jungkind et al.,(Eds), biology.(390),Plenum press.

Levy, S.B. 1998, The Challenge of Antibiotic resistance, Scientific American, New York 278(3):4653.

Lin, E.C.C.; Goldstein, R.; and Syvanerr, M. 1984. Bacteria, Plasmids and phages. An Introduction to Molecular biology. Cambridge, Mass: Harvard Univ. press. Pp 538.

Lorch, A. 1999. "Bacteriophages: An alternative to antibiotics?" Biotechnology and Development Monitor, 39:14-17.

Macaden R, and Bhat P. 1985. The changing pattern of resistance to ampicillin and cotrimoxazole in Shigella serotypes in Bangalore, South India. $J$. Infectious Diseases, 152:1348.

Magner, L. A. 1992. History of medicine. New York: Marcel Dekker.

Meleney, F.L. 1947. Treatment of surgical infections by chemical and antibiotic agents. Postgrad. Med; 1(2):87-96

Murray, B. 1985. Increasing resistance to trimethroprim-sulphamethoxazle among isolates of Escherichia coli in Developing Countries, J. Infectious Diseases, 152: 1107-1113.

Ogundipe, G.A.T., Oluokun, S.B. and Esuruoso, G.O. 1989. The development and efficiency of the animal health information system in Nigeria. Preventive Vet. Med., 7:121-135.
Osterholm, M.T. 1996. Emerging infectious diseases: a real public health crisis? (Guest editorial) Postgrad Med; 100(5):15-26

Prescott, L.M., Harley, J.P. and Klein, A. D. 2005. Drug Resistance, WCB McGraw-Hill, Microbiology $6^{\text {th }}$ International Edition, pp 1212.

Prusiner, S.B. 1996. Molecular biology and Pathogenesis of Prion diseases. Trends In Biochemical Sciences, 21: 482-7.

Robinson, D. 1976. The miracle finders: the stories behind the most important breakthroughs in medicine. New York: David McKay.

Welch, H.G. 1984. Antibiotic resistance: a new kind of epidemic. Postgrad. Med; 76(6):63-6

Wenzel R. 1995. Control of Antibiotic resistant Organisms, Journal of Infectious Disease and Antimicrobial Agents, 12 (1): 47-48.

White David G, Michael Moen and Darren Huber (1999) Trends in antibiotic resistance associated with $E$. coli calf scours. Alliance For The Prudent Use Of Antibiotics Department of Veterinary and Microbiological Sciences, North Dakota State University, Fargo, North Dakota, USA

World Bank 1995. Vietnam, poverty assessment and strategy, World Bank Country Operation Division, Country Department East Asia and Pacific Regions, January 1995.

World Health Organization (WHO).1993. How to investigate drug use in health facilities, WHO/DAP/93.1

World Health Organization, WHO (1999). Combating the growth of resistance to antibiotics. http://www.who.int/dap-icium/posters/2E1_txtf.html 